\title{
Multispectral MODIS data for visual interpretation of fog and low layer clouds
}

\author{
Karolina Krawczyk, Janusz Jasiński \\ Military University of Technology \\ Faculty of Civil Engineering and Geodesy \\ Institute of Geodesy, Department of Geographic Information Systems \\ 2 Gen. S. Kaliskiego St., 00-908 Warsaw, Poland \\ e-mail: karolina.krawczyk@wat.edu.pl; janusz.jasinski@wat.edu.pl
}

Received: 25 March 2015 / Accepted: 28 April 2015

\begin{abstract}
The paper presents the capability of applying selected modern remote sensing methods based on commonly available high spatial resolution MODIS images to fog and low layer clouds detection. Single spectral channel images, differential images and selected color compositions are analyzed for distinguishing the areas of the phenomena occurrence. Their internal structure and fog/cloud particles properties are assessed using brightness temperature and reflectance diagrams.
\end{abstract}

Keywords: remote sensing of the atmosphere, MODIS, fog, Stratus

\section{Introduction}

Fog and low layer clouds (Stratus) have direct influence on multiple activities of men. Limited visibility and degradation of atmospheric air quality caused by the meteorological phenomena occurrence may make land, sea and air traffic difficult and endanger numerous outside jobs. Entire independence of the activities' effectiveness and safety of the weather impact is not achievable. Prompt and precise assessment of the atmospheric conditions is then of great importance for support of miscellaneous fields of economy. Satellite data are a valuable source of information for detecting and monitoring of fog and Stratus. Recent developments in remote sensing techniques provided enhanced capabilities of research concerning the atmospheric phenomena. Unlike the synoptic observations conducted at the meteorological stations, satellite images are a source of spatially continuous data. It is of crucial importance especially in case of fog and low layer clouds detection in areas of sparse measurement networks.

Distinguishing between fog and low layer clouds by means of remote sensing methods is often impossible, mainly due to similar internal structure of the meteorological objects but also because of similar altitude of their occurrence above 
the ground. From the perspective of satellite observations, fog is observed as low layer clouds of zero altitude above the ground. For this reason, the issue of detecting them is usually treated jointly (Bendix et al., 2004).

There are currently numerous satellite systems providing images of various spatial, spectral, radiometric and temporal resolution (Qu et al., 2006; Krawczyk and Winnicki, 2012). The possibility to apply satellite images to fog and low layer clouds analysis and monitoring was already noticed in early 1970s (Hunt, 1973). The phenomena were mainly detected using data acquired at night time by means of the AVHRR radiometer installed onboard of the NOAA polar orbiting satellites. Basically, the differences of emissivity of the clouds and fog composed of small water droplets observed in the $3.7 \mu \mathrm{m}$ and $10.8 \mu \mathrm{m}$ spectral channels were used for detection (Bendix and Bachmann, 1991; Bendix, 2002).

Along with the development of the geostationary satellite systems and improvements in spatial resolution of their data, the approach was also introduced to analyses of images acquired by means of the SEVIRI and GOES radiometers (Ellrod, 1995; Underwood et al., 2004; Cermak et al., 2004). A method based on analyses of differential products occurred to be efficient also during day time for data acquired from both polar orbiting and geostationary satellites. However, some interpretation difficulties were indicated which were related to lighting changes at various elevation angles of the Sun and to problems concerning distinguishing fog and low layer clouds from surfaces covered with snow (Güls and Bendix, 1996).

A multispectral technique based on determining threshold values of reflectance and brightness temperature for various spectral ranges became a commonly developed method of fog and low layer clouds detection in the following years (Bendix et al., 2006; Cermak and Bendix, 2008). Research concerning analyses of radiation transfer in the atmosphere (Bendix et al., 2006) and analyses of parameters of spatial structures defined by spectral tests (Cermak and Bendix, 2008; Wen et al., 2009) was also conducted. The latter approach is still developed and it is followed by the authors of the paper as the main stream of the research concerning remote sensing of the atmosphere while this paper presents the capability of applying some selected modern remote sensing methods based on commonly available high spatial resolution MODIS images to fog and low layer clouds detection.

\section{Source Data}

The initial phase of satellite images preparation includes raw data processing for further analyses. Images acquired by the MODIS spectroradiometer (Moderate Resolution Imaging Spectroradiometer) (Qu et al., 2006) are the basic source of data for the research described in the paper. This multispectral optical and mechanical scanner is installed onboard of the Terra and Aqua polar orbiting satellites which are components of the EOS program (Earth Observing System). The MODIS has been providing images of global and regional processes occurring in the atmosphere, 
cryosphere and on the surfaces of the lands and oceans for over 10 years. High spectral and radiometric resolution of the data, advanced radiometric calibration systems installed onboard of the EOS program satellites and orbit stabilization with the accuracy of $\pm 5-10$ ' enable to obtain homogeneous observations series providing meteorologists with new capabilities of research concerning meteorological elements and phenomena (Qu et al., 2006).

The MODIS sensor records electromagnetic radiation in 36 spectral channels within the range of $0.4-14.4 \mu \mathrm{m}$. The MODIS provides data of nadir spatial resolution of $250 \mathrm{~m}$ in 2 spectral channels, $500 \mathrm{~m}$ in 5 channels and $1000 \mathrm{~m}$ in 29 channels. The Terra and Aqua satellites provide data including the area of Poland twice a day each (Table 1). The MODIS images are available at a few levels of preprocessing. Data of the L1B level, i.e. radiometrically and geometrically calibrated products, were used for the research. Table 2 presents a few selected web sites providing access to the MODIS data.

Table 1. Time of the MODIS flight over Poland (http://www.ssec.wisc.edu/datacenter/)

\begin{tabular}{|c|c|}
\hline Satellite & Flight time \\
\hline \multirow{2}{*}{ Terra } & $09: 05-10: 45$ UTC \\
\cline { 2 - 2 } & $19: 40-21: 15$ UTC \\
\hline \multirow{2}{*}{ Aqua } & $00: 15-01: 50$ UTC \\
\cline { 2 - 2 } & $10: 30-12: 20$ UTC \\
\hline
\end{tabular}

Table 2. Selection of web sites providing access to the MODIS data

\begin{tabular}{|l|l|}
\hline \multicolumn{1}{|c|}{ Type of available data } & \multicolumn{1}{c|}{ Web site } \\
\hline \multirow{2}{*}{$\begin{array}{l}\text { Data of various levels of } \\
\text { preprocessing - L1 through L4 }\end{array}$} & http://ladsweb.nascom.nasa.gov/data/search.html \\
\cline { 2 - 3 } Single spectral channels data & server ftp: ladsweb.nascom.nasa.gov/data/ftp_site.html \\
\hline \multirow{3}{*}{ Color compositions } & http://www.sat.dundee.ac.uk/abin/browse/modis \\
\hline & https://earthdata.nasa.gov/labs/worldview/ \\
\cline { 2 - 3 } & http://modis-atmos.gsfc.nasa.gov/IMAGES/index.html \\
\cline { 2 - 3 } & http://lance-modis.eosdis.nasa.gov/cgi-bin/imagery/realtime.cgi \\
\hline
\end{tabular}

The MODIS data are provided in files of the HDF format (Hierarchical Data Format) which is the standard of the EOS data recording. The Hydra 3.0.0 (Hyperspectral Viewer for Development of Research Applications) freely available application recommended by the World Meteorological Organization (http://cimss. ssec.wisc.edu/cspp/npp_hydra2_v1.0.shtml) was used for the data processing and analyses in order to detect areas of fog and low layer clouds. 
The application enables to:

- easily locate a pixel of the image and determine the value of the reflectance or brightness temperature recorded in it;

- create differential images using single spectral channels;

- generate color compositions;

- create scatter diagrams of pixel values in individual spectral channels;

- analyze selected groups of pixels in the scatter diagram which are automatically indicated in the image;

- create reflectance and brightness temperature profiles along a line segment indicated in the image.

The functionality of the Hydra application enables to process series of image data efficiently and intuitively. Development of satellite remote sensing techniques initiated also enhancement of research capabilities. However, proper interpretation of the data is still a problem. Therefore, a comprehensive approach to the miscellaneous satellite data and products analysis for developing tools in the form of unambiguous schemes or procedures for fog and low layer clouds detection is so important.

\section{Research Method}

The second phase of the images analysis for fog and low layer clouds areas detection is related to selection of spectral and spatial features characteristic for the meteorological phenomena. High spatial resolution data available in 36 spectral channels provide enhanced capabilities of fog and low layer clouds detecting as well as of determining the relations between the objects' features and the processes forming them. Multispectral analyses of the MODIS data, based mainly on the visible

\section{DAY TIME}
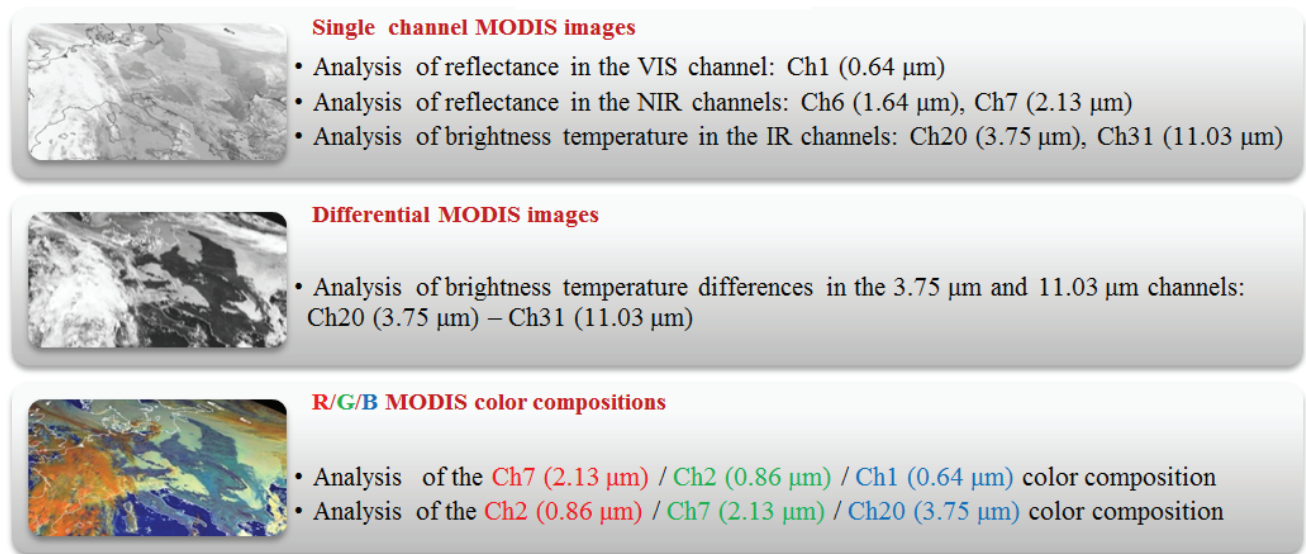

R/G/B MODIS color compositions

Analysis of the $\mathrm{Ch} 7(2.13 \mu \mathrm{m}) / \mathrm{Ch} 2(0.86 \mu \mathrm{m}) / \mathrm{Ch} 1(0.64 \mu \mathrm{m})$ color composition

- Analysis of the $\mathrm{Ch} 2(0.86 \mu \mathrm{m}) / \mathrm{Ch} 7(2.13 \mu \mathrm{m}) / \mathrm{Ch} 20(3.75 \mu \mathrm{m})$ color composition

Fig. 1. MODIS products proposed for fog and low layer clouds detection during day time (e.g.: Ch20 $(3.75 \mu \mathrm{m})$ - MODIS image in channel 20, central wavelength: $3.75 \mathrm{~mm}$ ) 
channels during the day time and on the infrared ones during the night time, use single spectral channel images, differential images and color compositions. Figures 1 and 2 present MODIS products proposed for fog and low layer clouds detection.

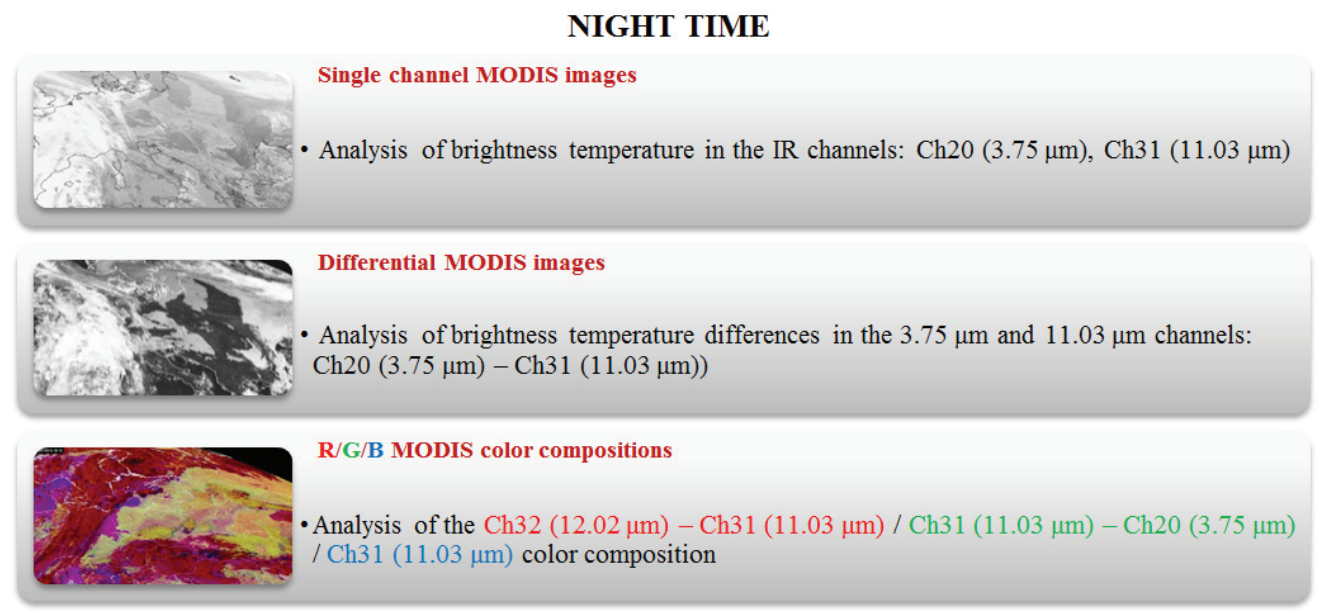

Fig. 2. MODIS products proposed for fog and low layer clouds detection during night time

\subsection{Single spectral channel images}

Fog and low layer clouds detection and monitoring may be based on single spectral channel images in the visible range $(\mathrm{Ch} 1-0.64 \mu \mathrm{m})$. The analysis takes into consideration both the typical values of reflectance and characteristic structure of the objects' tops, shape of their borders and compliance with the relief. The analysis may be enhanced using the near infrared channels images (Ch6 - 1.64 $\mu \mathrm{m}, \mathrm{Ch} 7-2.13$ $\mu \mathrm{m})$. Comparing them with images in the visible channel may indicate the prevailing processes in the objects. It may also facilitate distinguishing fog and low layer clouds from snow cover. They will be observed as smooth areas with distinct contours and moderate values of reflectance. The analysis may also include images in the thermal infrared channel $(\mathrm{Ch} 31-11.03 \mu \mathrm{m})$. Thermal properties of the tops of the emitting elements enable to distinguish between the cloud tops at various altitudes. Due to low altitudes of fog and Stratus tops, their brightness temperature is higher than for other clouds in the upper levels of the troposphere. However, the difference between the brightness temperatures of fog/Stratus and the underlying surface is so small that they cannot be distinguished (Bendix et al., 2004).

Detecting fog and Stratus using single images acquired in narrow spectral ranges is usually not easy. Analyzing images in more channels significantly increases effectiveness of detection. It is especially the case during day time when high resolution visible images are available for analysis of the internal structure and properties of the objects. 


\subsection{Differential images}

Detection and monitoring of the hazardous phenomena may also be conducted using differential images. The essence of the images is to indicate basic properties of an object using two appropriately selected spectral ranges. It is possible due to differences in emissivity, dispersion and absorption of radiation by clouds, land/water surface and atmosphere in the individual spectral channels recorded by the radiometer. For detection of fog and Stratus it is recommended to use differential images processed from MODIS data in the $3.75 \mu \mathrm{m}$ and $11.03 \mu \mathrm{m}$ channels (Bendix et al., 2004). It is the basic differential product for distinguishing atmospheric objects composed of small water droplets. During night time the algorithm utilizes the differences in emissivity of fog and Stratus in these channels which results in greater differences of brightness temperature. They are equal to a few degrees below zero distinguishing the objects from underlying surface and clouds in other levels of the troposphere. During day time the brightness temperature differences are positive due to solar radiation in the $3.75 \mu \mathrm{m}$ channel. The amount of radiation dispersed from elements in the atmosphere increases with decreasing dimensions of the particles of clouds. It is worth mentioning that reflectance of water droplets is higher than that of ice crystals. In most cases, fog and Stratus contain small water droplets, therefore the proposed set for differential images is the basic source of information used as a stand-alone product or as an element of color compositions described in the following section.

\subsection{Color compositions}

Color compositions produced by transparent combining images assigned to the individual composite colors of the RGB scheme are especially useful in detecting and interpreting fog and Stratus clouds. The process may combine single spectral channel images or differential ones. The European Organization for the Exploitation of Meteorological Satellites (EUMETSAT), running the Meteosat satellite system, provides recommendations concerning predefined color compositions for detecting and interpreting these meteorological objects on Meteosat images (Kerkmann et al., 2005; EUMETSAT User Service Division, 2004; WMO/EUMETSAT Workshop on RGB satellite products, 2012). The authors used these recommendations for the MODIS data processing. Proposals of color compositions for fog and Stratus detection are presented in Fig. 1 and Fig. 2.

\section{Data analyses examples}

Day time analysis - March 2, 2014, 9.55 UTC. The area of Poland was influenced by a vast high pressure system with its center over northern part of Russia. The high covered the area from Scandinavia through Central Europe to Turkey. Fog and mist 
developed at night and in the morning in low pressure gradient areas of weak southern and eastern wind, especially in the areas where it had rained the previous day (http:// www.meteo.sp.mil.pl).

Analysis of the MODIS images in single spectral channels acquired on March 2, 2014 at 9.55 UTC together with reflectance and brightness temperature profiles along selected line segments facilitates distinguishing the objects from cloudless areas and clouds in the upper levels of the troposphere (Fig. 3 and Fig. 4). The fog/Stratus is observed as smooth areas of higher values of reflectance as compared with the cloudless areas and lower reflectance values with respect to clouds reaching the moderate and high levels of the troposphere (Fig. 4). Characteristically significant value of the brightness temperature difference between the $3.75 \mu \mathrm{m}$ and the 11.03 $\mu \mathrm{m}$ spectral ranges for the objects is also observed (Fig. 3). The changes of shades in the images related directly to the changes of reflectance or brightness temperature seem to contain the majority of information concerning the analyzed phenomena. However, the texture, size, shape and relations between the objects' elements occur
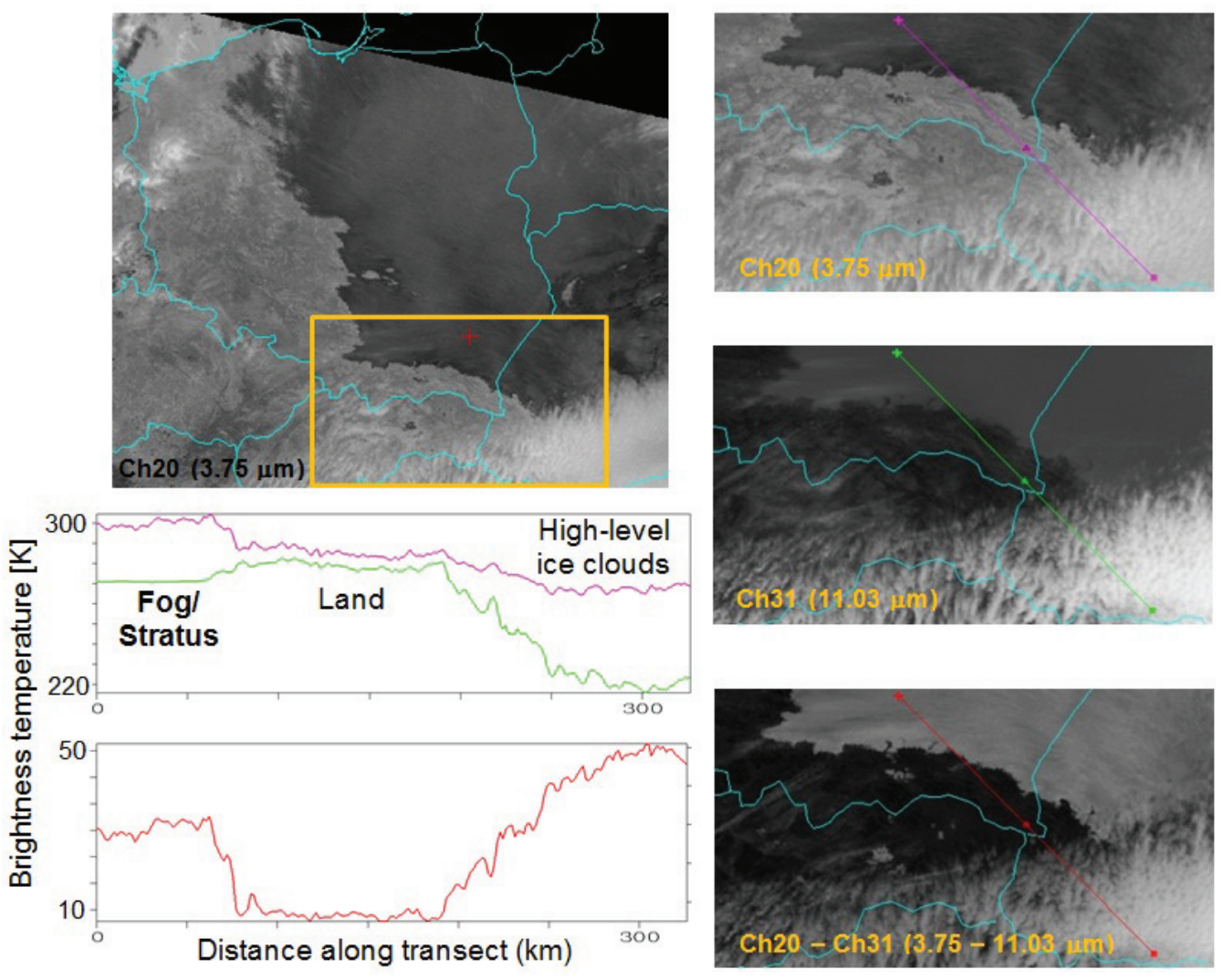

Fig. 3. The MODIS satellite images of March 2, 2014 at 9.55 UTC indicating the thermal properties of fog and Stratus 
to be equally important characteristics for the analysis. Fog and Stratus are imaged as layers of regular contours or contours compliant with the relief in hilly areas. High resolution of the MODIS data enables to analyze the features in detail for unambiguous detection.
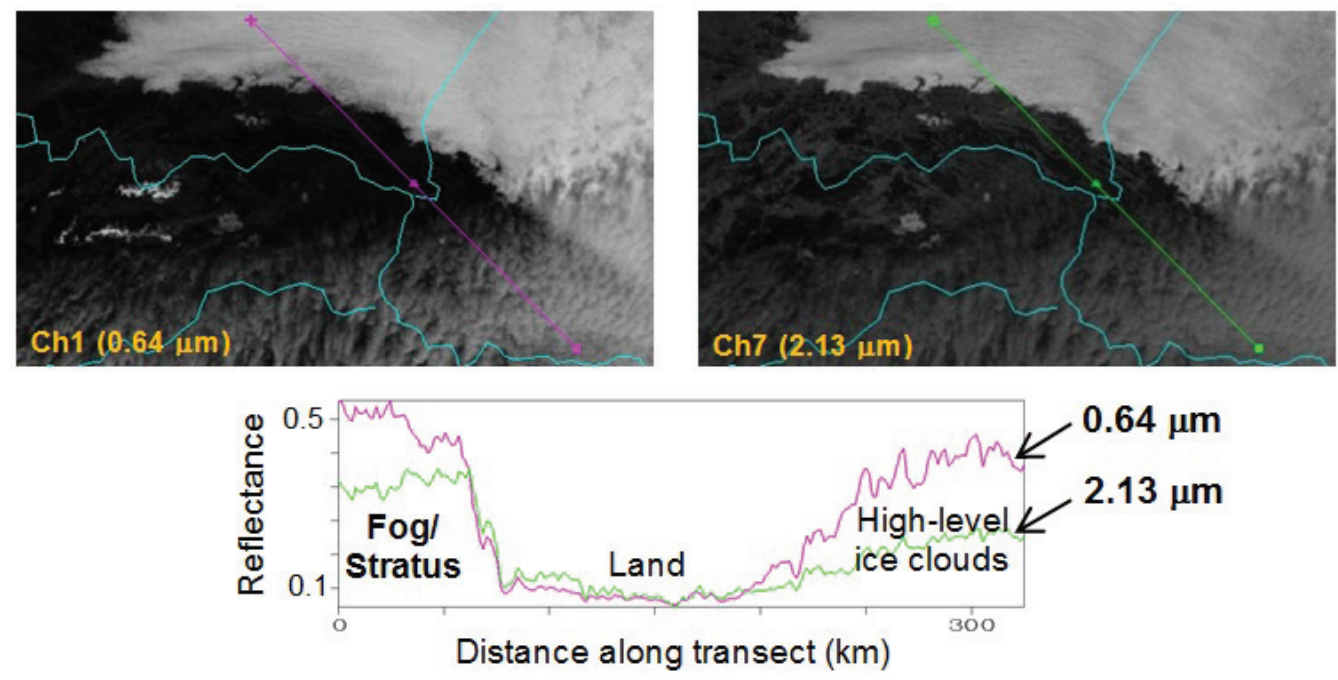

Fig. 4. The MODIS satellite images of March 2, 2014 at 9.55 UTC indicating the reflectance of fog and Stratus

The ability to distinguish defined patterns in images is of crucial importance for interpreting color compositions. Two RGB products are proposed in the paper for day time analyses (Fig. 5). One of them (RGB Ch7 $(2.13 \mu \mathrm{m}) / \mathrm{Ch} 2(0.86 \mu \mathrm{m}) /$ Ch1 $(0.64 \mu \mathrm{m}))$ is based on reflectance in three spectral ranges varying with the size, number and physical state of the particles of the clouds. Fog and low layer clouds have similar albedo in all the spectral ranges used for the composition. They are composed of water droplets which results in increased reflectance in channel 7 (2.13 $\mu \mathrm{m})$. Due to increased absorption of radiation by ice crystals, the channel may be used for distinguishing between clouds composed of water droplets and ice crystals. The latter are presented in the characteristic for the composition blue color while fog and Stratus are white with pink shade.

In the other proposed composition (RGB Ch2 $(0.86 \mu \mathrm{m}) / \mathrm{Ch} 7(2.13 \mu \mathrm{m}) / \mathrm{Ch} 20$ $(3.75 \mu \mathrm{m})$ ), the properties of the $3.75 \mu \mathrm{m}$ spectral range are used along with the information related to reflectance in the $0.86 \mu \mathrm{m}$ and $2.13 \mu \mathrm{m}$ channels. The amount of radiation recorded in this channel depends on the dimensions and physical state of the cloud particles. Since fog and Stratus are built of small water droplets, their brightness temperature has significant values. These elements are presented in this composition as light smooth areas (Fig. 5) and they are clearly distinct from ground (dark blue) or moderate and high level clouds (shades of orange). 

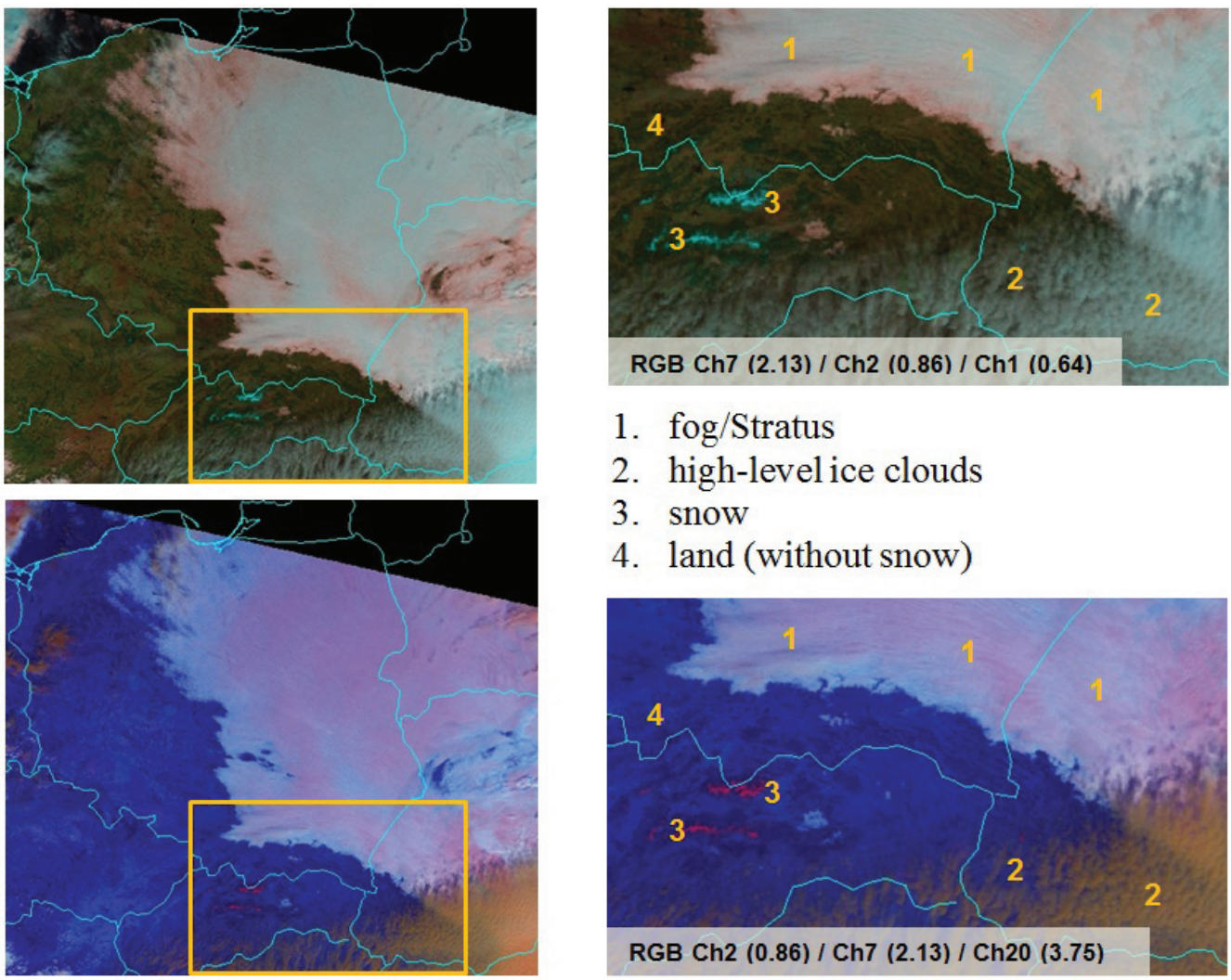

\section{1. fog/Stratus \\ 2. high-level ice clouds \\ 3. snow \\ 4. land (without snow)}

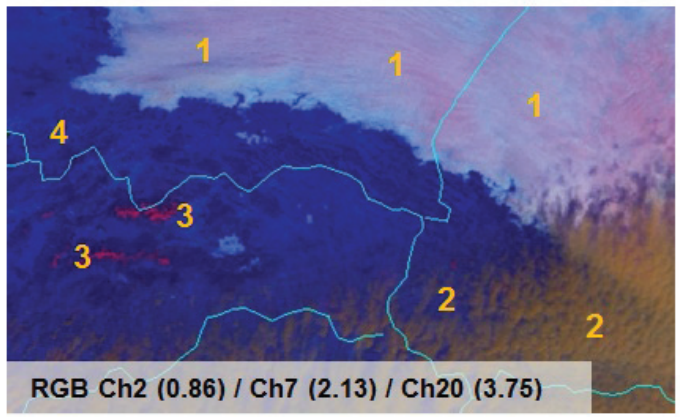

Fig. 5. The MODIS satellite images of March 2, 2014 at 9.55 UTC

Night time analysis - March 1, 2014 - 20.20 UTC. Fog and mist developed in northern and eastern Poland along with dissipating cloud cover in the evening after light rain during the day. Fog was detected in the area using analysis of brightness temperature diagrams and information concerning relations between areas of land, sea and clouds observed in images in the individual spectral channels and color compositions (Fig. 6 and Fig. 7). It is worth to note the small thermal contrast between the fog and the underlying surface observed in the $11.03 \mu \mathrm{m}$ and $3.75 \mu \mathrm{m}$ channels. Fog detection in single spectral channel images is in this case difficult. Therefore, it is appropriate to use differential images $(\mathrm{Ch} 20(3.75 \mu \mathrm{m})-\mathrm{Ch} 31(11.03 \mu \mathrm{m}))$ and color composition of the following MODIS channels: Ch32 $(12.02 \mu \mathrm{m})-\mathrm{Ch} 31(11.03 \mu \mathrm{m})$ / Ch31 $(11.03 \mu \mathrm{m})-\mathrm{Ch} 20(3.75 \mu \mathrm{m}) / \mathrm{Ch} 31(11.03 \mu \mathrm{m})$. The characteristic yellow and green color of the structures analyzed in the paper is related to high values of the red and green components which results from significant optical density of fog/ Stratus and from differences in their emissivity in the $3.75 \mu \mathrm{m}$ and $11.03 \mu \mathrm{m}$ channels (Fig. 7). 

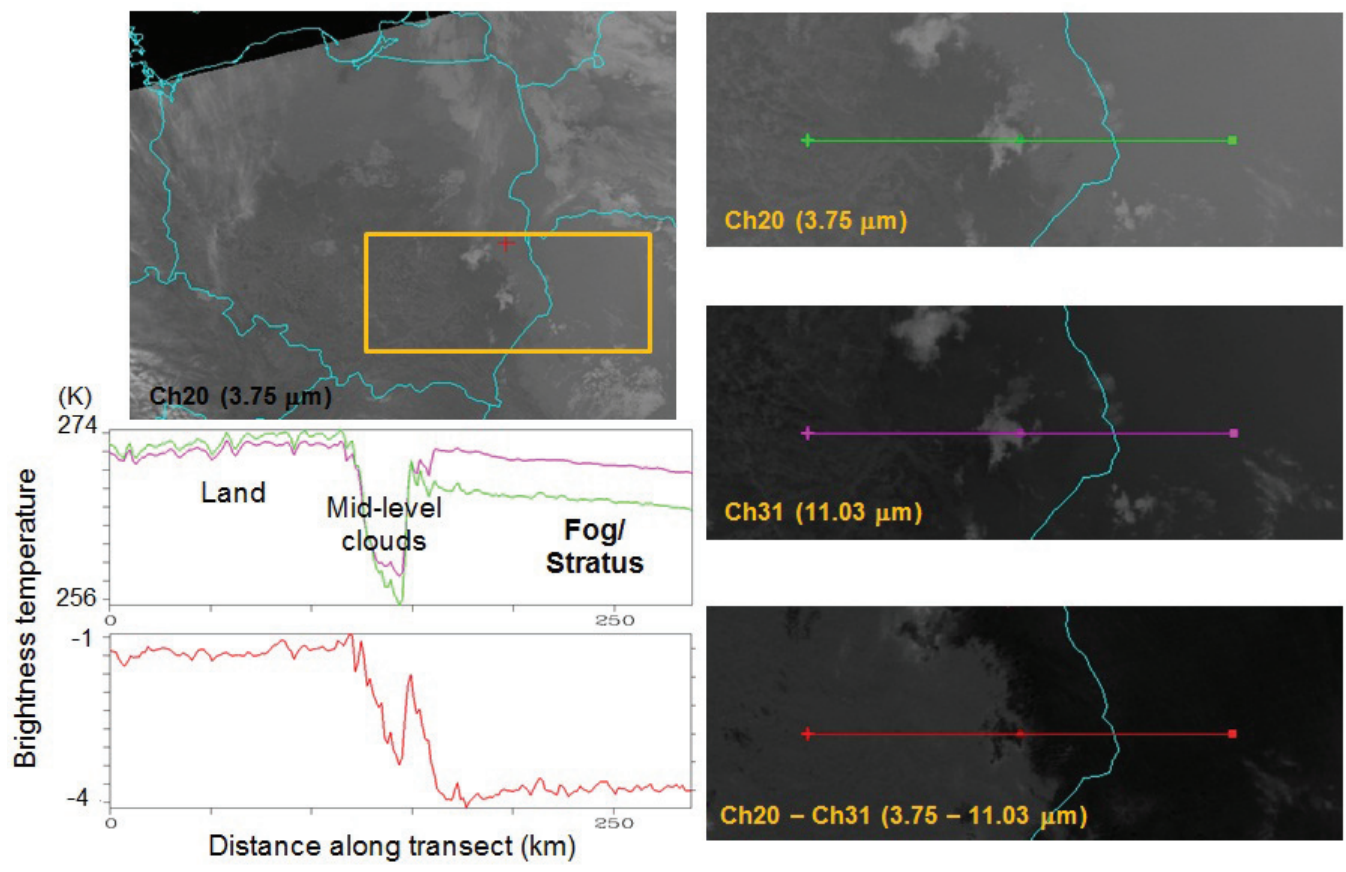

Fig. 6. The MODIS satellite images of March 1, 2014 at 20.20 UTC indicating the thermal properties of fog and Stratus
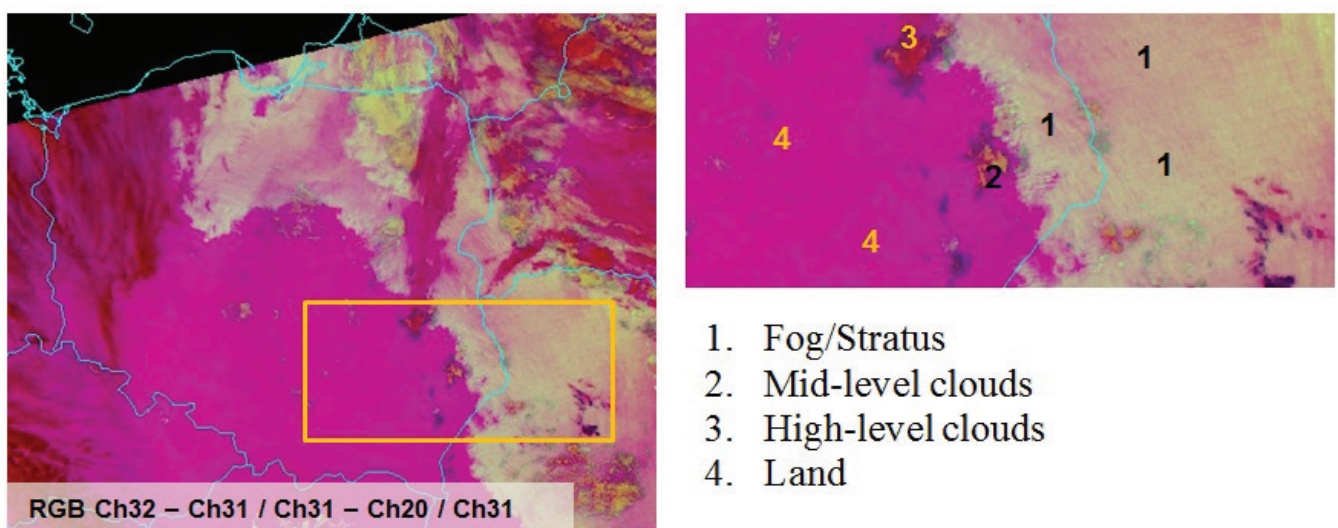

1. Fog/Stratus

2. Mid-level clouds

3. High-level clouds

4. Land

Fig. 7. The MODIS satellite images of March 1, 2014 at 20.20 UTC 


\section{Conclusions}

Fog and low layer clouds may be of small horizontal dimensions which, due to the mean distance between synoptic stations of about $70 \mathrm{~km}$, may cause that they are not identified during the surface observations. Satellite images are a valuable source of information for detecting the objects. The method of the data application for the purpose proposed in the paper provides an efficient tool for detecting and quick and precise locating of fog and Stratus areas. The conclusions from the weather conditions analyses based on the current data may be successfully used in operational meteorological support provided by weather stations. The meteorological data may also be used by personnel of crisis management teams, road maintenance services and air traffic management services. In many cases their access to the individual satellite images and synoptic data is limited. The presented possibilities to use commonly available sets of multispectral MODIS data for detecting phenomena that have direct influence on visibility may be of significant importance for organizations providing services and information dependent on it. One of the main advantages of the MODIS technology is the capability to quickly and efficiently survey large areas with high spatial resolution. On the other hand, the images are available with low temporal resolution which may be a limitation in some applications. The MODIS system provides information from the area covering Poland four times a day, however, the area is imaged in the morning, in the evening and at night which is the time when the frequency of fog and Stratus occurrence is the highest.

Fog and low layer clouds are the main cause of numerous accidents in road transport and sea and air navigation. Limited visibility is a factor extremely complicating air operations - causing cancellations or rescheduling of flights. They have significant impact on the safety of passengers and maintenance personnel as well as airport and aircraft. Air, sea and land transport operations history recorded severe accidents that took place in situations when the weather conditions could not be analyzed and assessed in sufficient detail due to lack of synoptic data from surface weather stations. In those cases, the capability to fill the gap with satellite data analysis results could be a crucial supplement of the meteorological support.

\section{Acknowledgements}

The research was conducted and the paper was prepared by the personnel of the Department of Geographic Information Systems within Research project No 23854. 


\section{References}

Bendix, J. and Bachmann, M. (1991). A method for detection of fog using AVHRR-imagery of NOAA satellites suitable for operational purposes (in German). Meteorologische Rundschau, 43, 169-178.

Bendix, J. (2002). A satellite-based climatology of fog and low-level Stratus in Germany and adjacent areas. Atmospheric Research, 64, 3-18.

Bendix, J., Cermak, J. and Thies, B. (2004). New perspectives in remote sensing of fog and low Stratus - TERRA/AQUA-MODIS and MSG. Proceedings 2004 Third International Conference on Fog, 11 - 15 October 2004, Cape Town.

Bendix, J., Thies, B. and Nauß, T. (2006). A feasibility study of daytime fog and low stratus detection with TERRA/AQUA-MODIS over land. Meteorological Applications, 13, 111-125. DOI: 10.1017/ S1350482706002180

Cermak, J., Thies, B. and Bendix, J. (2004). A new approach to fog detection using SEVIRI and MODIS data. Proceedings 2004 EUMETSAT Meteorological Satellite Users' Conference Prague, 31 May - 4 June 2004, Czech Republic (https://www.eumetsat.int/website/wcm/idc/idcplg?IdcService $=$ GET_FILE\&dDocName=PDF_CONF_P41_S2_CERMAK_P\&RevisionSelectionMethod=Latest Released\&Rendition=Web).

Cermak, J. and Bendix, J. (2008). A novel approach to fog/low Stratus detection using Meteosat 8 data. Atmospheric Research, 87, 279-292.

Ellrod, G.P. (1995). Advances in the detection and analysis of fog at night using GOES multispectral infrared imagery. Weather and Forecasting, 10, 606-619.

EUMETSAT User Service Division. (2004). Best practices for RGB compositing of multispectral imagery. Darmstadt.

Güls, I. and Bendix, J. (1996). Fog detection and fog mapping using low cost Meteosat-WEFAX transmission. Meteorological Applications, 3, 179-187.

Hunt, G.E. (1973). Radiative properties of terrestrial clouds at visible and infrared thermal window Wavelengths. Quarterly Journal of the Royal Meteorological Society, 99, 346-369.

Kerkmann, J., Rosenfeld, D. and Bridge, G. (2005). Applications of Meteosat Second Generation (MSG) - RGB images: part 04 - RGB composites with channels 01-11 and their interpretation. EUMETSAT, Darmstadt.

Krawczyk, K. and Winnicki, I. (2012). Wielospektralne dane satelitarne w interpretacji mgieł i niskich chmur warstwowych. Biuletyn WAT, 4, 21-37.

Qu, J. J., Gao, W., Kafatos, M., Murphy, R. E. and Salomonson, V. V. (2006). Earth Science Satellite Remote Sensing. Vol. 1: Science and Instruments. Tsinghua University Press, Springer.

Underwood, S.J., Ellrod, G.P. and Kuhnert, A.L. (2004). A multiple-case analysis of nocturnal radiationfog development in the central valley of California utilizing the GOES nighttime fog product. Journal of Applied Meteorology, 43, 297-311.

Wen, X., Liu, L., Li, W. and Dong, P. (2009). An object-oriented based daytime over land fog detection approach using EOS/MODIS data. Proceedings of SPIE - The International Society for Optical Engineering 7475, Remote Sensing of Clouds and the Atmosphere XIV, 747516, 29 September 2009. DOI: $10.1117 / 12.830163$

WMO/EUMETSAT workshop on RGB satellite products: Standards, Applications and Opportunities

- final report. (2012). 17-19 September 2012, Germany, Seeheim.

http://cimss.ssec.wisc.edu/cspp/npp_hydra2_v1.0.shtml

https://earthdata.nasa.gov/labs/worldview/

http://ladsweb.nascom.nasa.gov/data/search.html

http://modis-atmos.gsfc.nasa.gov/IMAGES/index.html

http://lance-modis.eosdis.nasa.gov/cgi-bin/imagery/realtime.cgi

http://www.meteo.sp.mil.pl

http://www.sat.dundee.ac.uk/abin/browse/modis

http://www.ssec.wisc.edu/datacenter/ 


\title{
Wielospektralne dane MODIS w wizualnej interpretacji mgiel i niskich chmur warstwowych
}

\section{Karolina Krawczyk, Janusz Jasiński}

\author{
Wojskowa Akademia Techniczna \\ Wydział Inżynierii Lądowej i Geodezji \\ Instytut Geodezji, Zakład Systemów Informacji Geograficznej \\ ul. Gen. S. Kaliskiego 2, 00-908 Warszawa, Polska \\ e-mail: karolina.krawczyk@wat.edu.pl; janusz.jasinski@wat.edu.pl
}

\section{Streszczenie}

Artykuł przedstawia możliwości zastosowania wybranych współczesnych metod teledetekcyjnych opartych na powszechnie dostępnych zobrazowaniach MODIS o wysokiej rozdzielczości do wykrywania obszarów mgieł i niskich chmur warstwowych. Do wykrywania obszarów występowania tych zjawisk wykorzystywane są wyniki analiz zobrazowań w pojedynczych kanałach spektralnych, zobrazowania różnicowe oraz wybrane kompozycje barwne. Wewnętrzna struktura zjawisk i własności cząstek mgły/ chmur warstwowych analizowane są na podstawie diagramów temperatury radiacyjnej i odbiciowości. 